MEDIEVAL ART IN MOTION 


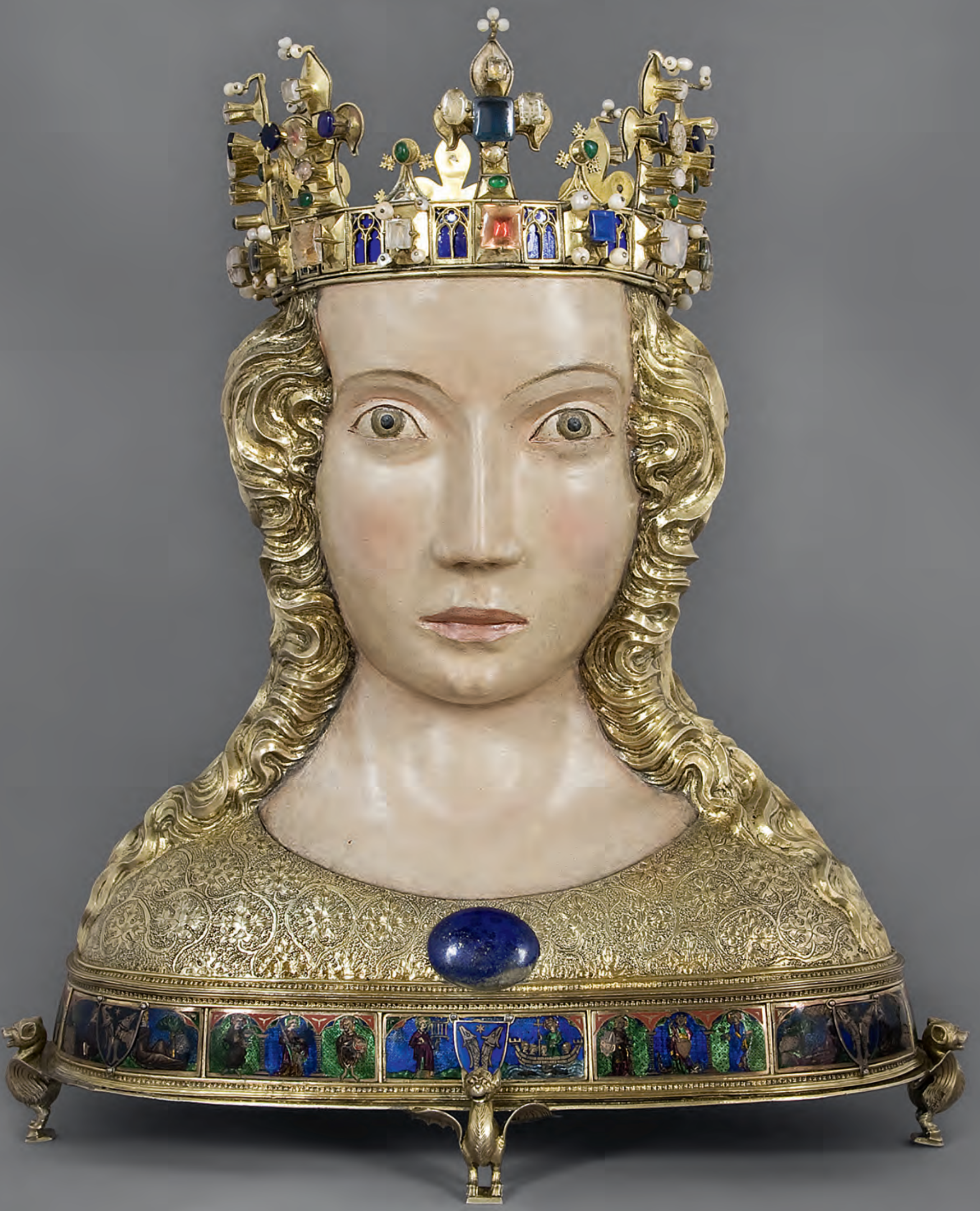


MARIAH PROCTOR-TIFFANY

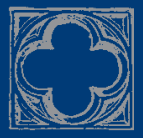

\section{Medieval Art in Motion}

The Inventory and Gift Giving of Queen Clémence de Hongrie 


\section{A \\ ART HISTORY}

PUBLICATION INITIATIVE

This book is made possible by a collaborative grant from the Andrew W. Mellon Foundation.

Library of Congress Cataloging-in-Publication Data

Names: Proctor-Tiffany, Mariah, 1971- author.

Title: Medieval art in motion : the inventory and gift giving of Queen Clémence de Hongrie / Mariah Proctor-Tiffany.

Description: University Park, Pennsylvania : The Pennsylvania State University Press, [2018] | Includes bibliographical references and index.

Summary: "Reconstructs the art collection and material culture around the fourteenth-century French queen Clémence de Hongrie. Examines how she moved her objects in a deliberate strategy to build her identity and create a lasting legacy for herself and her family in medieval Paris" -Provided by publisher.

Identifiers: LCCN 2018026636 | ISBN 9780271081120 (cloth : alk. paper)

Subjects: LCsH: Clementia, of Hungary, Queen, consort of Louis X, King of France, 1293-1328-Art collections. | Clementia, of Hungary, Queen, consort of Louis X, King of France, 1293-1328-Art patronage. | Art-Collectors and collecting-France-Paris-History-To 1500. | Art Patronage-France-Paris-History-To 1500. | Art, Medieval-France-Paris. | Gifts-France-HistoryTo 1500 .

Classification: LCC N5262.C56 P76 2018 | DDC 709.402-dc23 LC record available at https://lccn.loc.gov/2018026636
Copyright (C) 2019 Mariah Proctor-Tiffany

All rights reserved

Printed in China

Published by The Pennsylvania State University Press,

University Park, PA 16802-1003

The Pennsylvania State University Press is a member of the Association of University Presses.

It is the policy of The Pennsylvania State University Press to use acid-free paper. Publications on uncoated stock satisfy the minimum requirements of American National Standard for Information Sciences-Permanence of Paper for Printed Library Material, ANSI Z39.48-1992.

Additional credits: Cover, attributed to Jean de Touyl, reliquary shrine of Elizabeth of Hungary (fig. 55); frontispiece, detail, reliquary head of one of the Eleven Thousand Virgins (fig. 56); pp. vi-vii, detail, first page of the inventory of the belongings of Clémence de Hongrie (fig. 4). 
For Scott, Maquelle,
and Corinn 


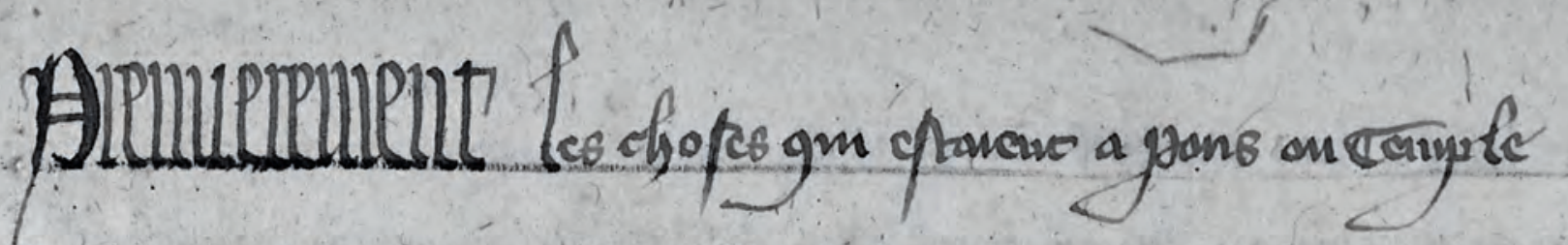

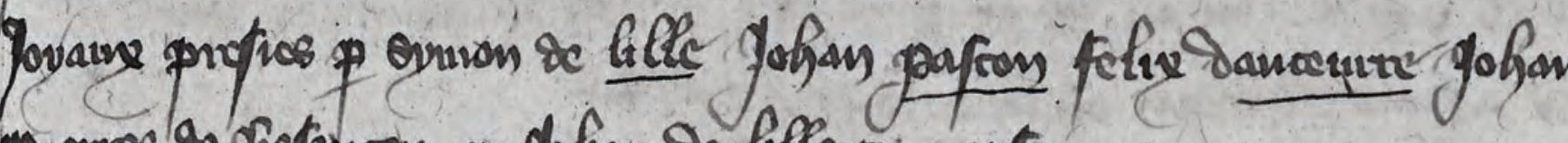

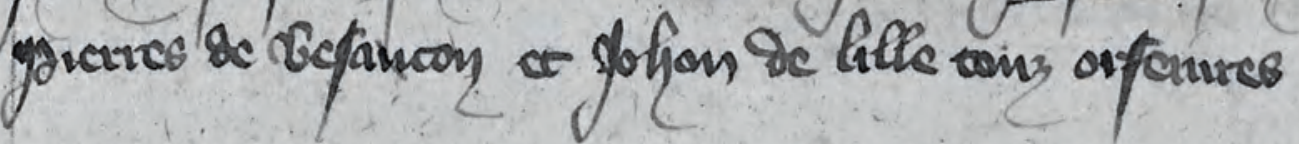

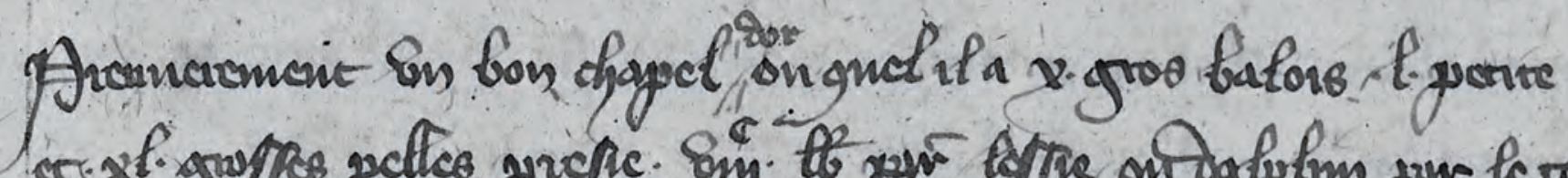

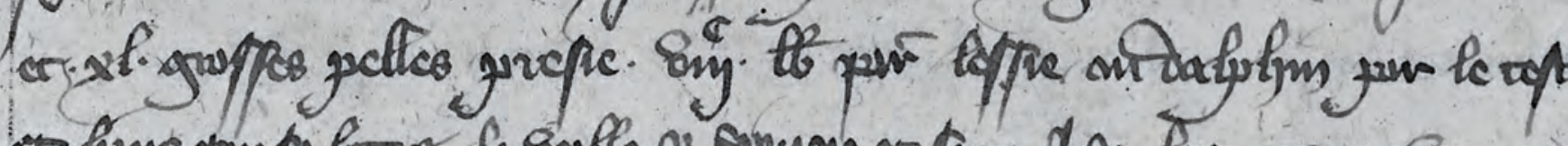

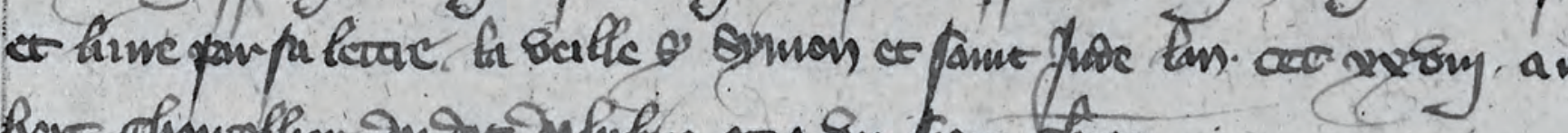

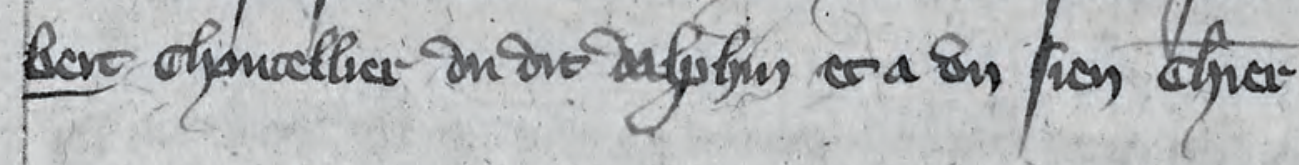

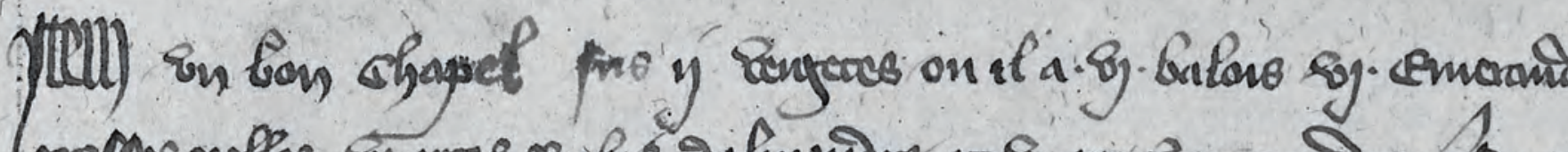

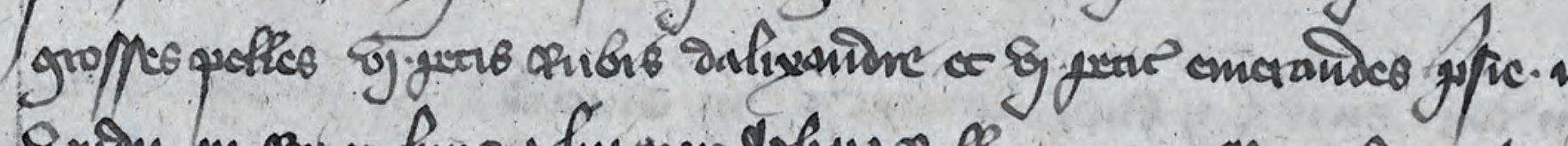

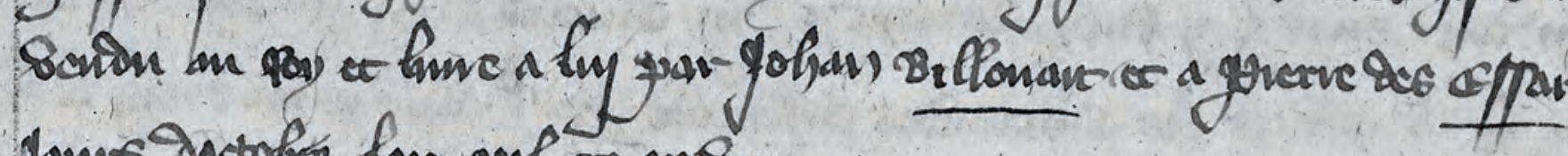

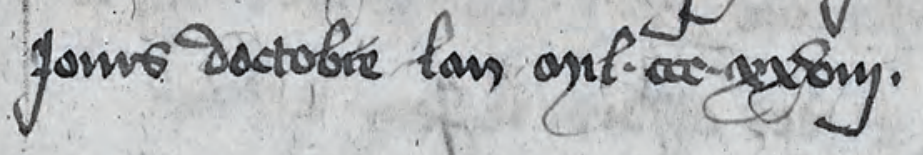

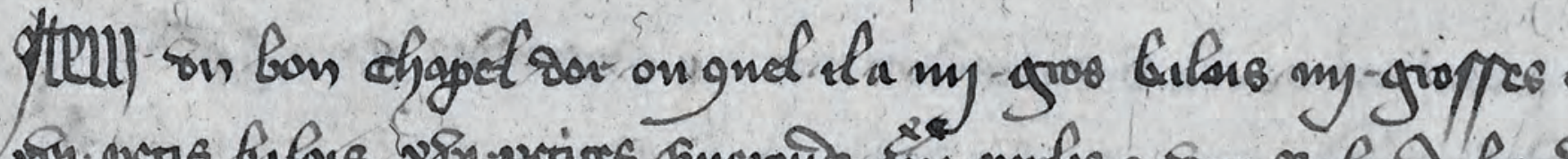

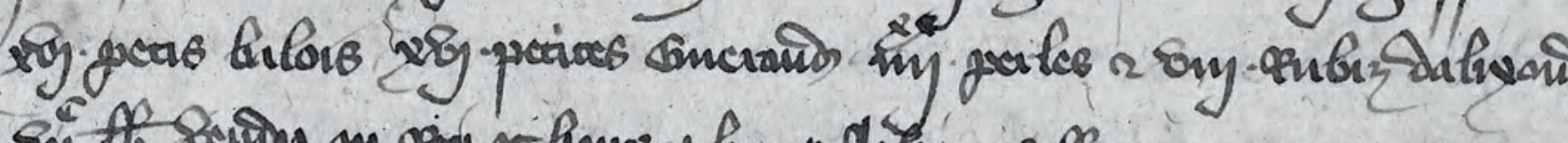

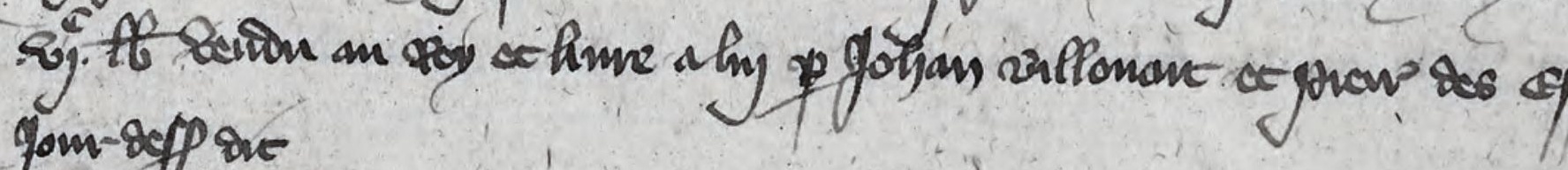
gom-iefpare 